\title{
1. Regulating telecommunications in the EU
}

\subsection{THE POLITICS OF TELECOMMUNICATIONS}

On 2 March 1791, less than two years after the outbreak of the French Revolution, a message was relayed from Parcé-sur-Sarthe to Brûlon in France across a system of optical telegraphs designed by Claude Chappe, thus officially commencing the era of telecommunications. Although more than two centuries have passed since that day, the desire that drove that and every single other invention in telecommunications since has been the same: instant conveyance of signals across large distances. The means of such conveyance have changed significantly since 1791: optical systems were replaced with wired telegraphs, telephones with mobile telephones, aerial television with cable and satellite, and, ultimately, the Internet became the ubiquitous and universal network. What has not changed, however, is the motivation behind the desire to convey information quickly: power. Since those who control information also hold political power, telecommunications almost instantly became a political issue. $^{1}$

The politics of telecommunications have, in the past centuries, revolved around ownership, control and access to technical means of communications. Laying out cables or setting up telecommunications poles required risky investment and could be undertaken either by the state itself or by very large companies. Reaping benefits from the investment, in turn, was only possible if relative control over the assets and access thereto could be maintained. This meant that states often needed to intervene to change the balance of powers, thus setting the stage for what we today call telecoms regulation. Today, development and innovation in this area require investment on a colossal scale, just as it did in the nineteenth century. This often means that companies who were there first - the incumbents - were able to reap the benefits of their

1 See Daniel R. Headrick, The Invisible Weapon: Telecommunications and International Politics, 1851-1945 (Oxford University Press, Oxford 2012). 
astuteness. ${ }^{2}$ It has also meant that maintaining competition became and remained the primary focus for regulators. Those who wanted to compete usually had no means of investing in laying their own cables, masts, satellites and other equipment. They had to lobby for access to the already existing ones. If they managed to build their own networks, they became concerned with whether the dominant providers would allow them interconnection with the rest of the network. The users subject to monopolies, on the other hand, worried about universal service - whether the basic service was reasonably accessible to them. All this, in turn, led to issues concerning privacy and national security. As will be seen below, telecoms regulation had been only very limited until the 1980s. At that point the regulatory focus changed from managing the 'natural' monopolies to liberalisation and the removal of monopolies - a regulatory pattern which is still valid today.

Telecommunications monopolies have profound effect not only for users and companies, but also for a country's global economic standing. ${ }^{3}$ Countries or regions that have successfully been able to break or weaken these legacy monopolies often benefited from faster and more reliable next-generation networks (NGN). But tradeoffs were required too. Monopolies often made sense, as single firms could serve the entire market more efficiently than multiple firms or the state. It was convenient to allow the monopolist to do the job nobody else could. This is the single reason behind the fact that regulation of competition stands behind all telecommunications regulation: fully competitive markets are difficult or impossible to achieve but regulation can get us as near to them as possible. Today, the question is often: what regulatory model is best suited for achieving most competition in the telecommunications sector? In Europe, this model is known as sector-specific or ex ante regulation. ${ }^{4}$

The emergence of the Internet in the final decade of the twentieth century, and its global ascendance as the universal medium of communication in the twenty-first, made telecommunications regulation significantly more political, more difficult to understand and more important than had hitherto been the case. In her 2014 study, deNardis says that 'internet governance conflicts are the new spaces where political and

2 Ibid., chapter 1.

3 For more on competition in telecommunications, see Chapter 4. On how telecommunications monopolies affect the Internet in the United States see Susan Crawford, Captive Audience: The Telecom Industry and Monopoly Power in the New Gilded Age (Yale University Press, New Haven and London 2013).

4 See Chapters 4 and 6. 
economic power is unfolding in the twenty-first century'. 5 Arrangements of technical architecture are arrangements of power. Having an influence over the carrier gives the subject the power over social order. Understanding the dynamics of global power means understanding the dynamics of telecommunications regulation. That regulation has never been more challenged and uncertain than it is today. Telecommunications companies have never suffered as much competition in their traditional businesses (voice, messaging, TV) as they do today, when alternative business models that run on the Internet (VoIP, IM, on-demand TV) flourish.

Political and public debates on telecoms today tend to be loud, and opinions on issues as diverse as broadband availability, mobile pricing and net neutrality are often delivered in dramatic tones. In reality, understanding telecommunications lawmaking has always been challenging. Telecommunications policy is usually years in the making, often with only incremental changes being made and with the general public (and sometimes the regulator itself) ill-informed about the meaning of the technical terms or the implications of particular regulatory choices. In the European context, there are several specific difficulties which make understanding the politics of Internet regulation challenging.

First, the modern Internet is divided between two regulatory layers. The first regulates the carrier - the wires covering the signal; the second regulates the content - the substance running on the wires. The first has traditionally been subject to a discipline called telecommunications law, ${ }^{6}$ while the second is regulated under the media and/or electronic commerce laws. But, while this silo division made sense 20 years ago, it no longer does today, and there are increasing calls for the laws to be more flexible. ${ }^{7}$ Convergence of services means that conveyance of telephone, video and data is taking place using a single network. Instead of using telephone wires for telephone calls, Internet wires for data and spectrum for broadcast signals, all services are increasingly run only on the Internet. But the legislation in force today and the political processes that inform it still largely operate with the old regulatory models. Put in different words, the pre-convergence laws and regulatory authorities need

\footnotetext{
5 Laura DeNardis, Global War for Internet Governance (Yale University Press, New Haven and London 2014).

6 The official EU term since 2002 is 'electronic communications'.

7 See, for instance, Alexandre de Streel and Pierre Larouche, An Integrated Regulatory Framework for Digital Networks and Services, A CERRE Policy Report, 27 January 2016, CERRE, available at http://www.cerre.eu/publications/ integrated-regulatory-framework-digital-networks-and-services-0.
} 
to match the convergence reality of new communications patterns. ${ }^{8}$ At present, we do not know how that is to be achieved. Regulatory layers are political and value-laden both by design and by the effect they produce. Arrangements of Internet layers, even when technical in nature, are arrangements of power. As DeNardis argued, changing the architecture on which the Internet is built also changes the politics it constructs, ${ }^{9}$ which means that electronic communications influence the political process and are, in turn, influenced by it.

Second, the fast-changing, modular and decentralised reality of modern telecommunications demands a more functional regulatory model than the one built for legacy technologies. The traditional regulatory model was easily applied to distinct technologies: telephones, telegraphs, linear television, and so on. The political processes that influence telecommunications and the agencies in charge of enforcing them are a result of legacy technologies and legacy ways of thinking. In the world of converged technologies and services, this no longer makes sense. The EU recognised this problem relatively early, as is apparent from its allowing both sector-specific regulation and competition law to apply to this area, as well as from the mix of liberalisation and harmonisation which it used. More is needed. Research in recent years has intensified calls for simplification in the form of only two frameworks - one for digital networks, the other for services running on those networks. At present, we have not discovered a natural path for achieving optimal legislation.

The third reason for the modern difficulties is the division between regulatory competences. Telecommunications are primarily regulated nationally - by each individual state. But, in addition to this, they are subject to various international standards and, occasionally, rules. At European level, this means that there are two frameworks that influence telecommunications - national and European. There is no single European body of law that covers the totality of telecommunications and both rule making and enforcement are divided between Member States and the EU, necessitating political compromises and sensitive coordination. The processes that inform and influence modern telecommunications are global. Not only are undertakings involved in telecoms increasingly global, but the infrastructure is shared and often requires cooperation between several states. The politics of telecoms regulation is, therefore, increasingly international.

8 See Jonathan Neuchterlein and Philip Weiser, Digital Crossroads: Telecommunications Law and Policy in the Internet Age (2nd edition, The MIT Press, Cambridge, Massachusetts 2013), p. 20.

9 DeNardis (2014). 
A direct corollary of this is the complex interplay of European, international and national matters, which has an obvious implication for the institutional structures that oversee the implementation of laws: competences are divided, often shared and occasionally conflicting. There is no single EU institution overseeing the implementation of EU laws. In the early days of liberalisation, this division led to a battle of competences. Litigation was intense and the involvement of both national and EU institutions exceptional. Today, it means that national regulatory authorities (NRAs) are institutionally the most relevant factors. But the issue is more complex still. Since multiple laws from different layers and multiple international authorities may compete for competence, modern telecoms is always by default a result of institutional compromises.

Fifth, the old world of telecommunications was the world of regulation - laws were passed by national governments. The new world of telecoms is the world of governance - networks are no longer just regulated, they are governed - by different actors, and at different levels. The new reality of telecoms is that passing national laws is only part of the story. Large multinational corporations can take decisions which have instant global impact. It is often uncertain to what extent such corporations may be subject to national laws, and what consequences the lawmaking originating in one major geographic area may have in others.

\subsection{WHAT IS REGULATED}

Telecommunications (or electronic communications), in the simplest terms, concerns itself with the transmission of signals. The signals consist of information - words, messages, images, sounds or any combination thereof. The transmission takes places through networks, usually comprising fixed (copper and fibre wires), mobile (wireless) and satellite and cable. However, telecommunications also consists of specific transmission services provided on these networks. Thus a broadband cable can provide the Internet but also TV channels, and a copper wire can be used for the provision of fixed telephony but also to provide broadband Internet. Each of these are considered to be a different service. Networks and services, ${ }^{10}$ in colloquial terms, are signal carriers. Demarcated in such terms, telecommunications regulation does not concern itself with the content that runs on networks but only with the transmission process itself. Historically, different networks and services were

10 To this should also be added terminal equipment attached to the networks. 
subject to different laws, often coinciding with the emergence of respective technologies. In the United States, laws covering interconnection between different telephone networks in the early twentieth century only became relevant where the lack of interconnection between competing networks became a problem. AT\&T as a monopoly was subjected to such regulation in 1913, becoming a regulated monopoly. Laws covering radio spectrum came about in 1927 as a response to overcrowding and interference. These patterns indicate that telecommunications regulation developed as a patchwork of individual regulatory efforts around different phenomena that all shared similar technological, economic and social features but which were not targeted by distinct and coherent policy movements. Telecoms regulation was, from its earliest days up to the great liberalisation movement in the 1980s, a way to manage monopolies rather than eliminate them.

For decades this 'silo' approach to policymaking has been dominant on both sides of the Atlantic. Its main feature is that regulatory policies and laws are structured by industry, sector and type of content, so that networks and services that belong to a particular type are regulated together. This type of intervention is also sometimes referred to as 'vertical', since different vertical subdivisions or 'silos' of regulation exist. Thus wirelines telephony, mobile telephony, TV and radio, and cable and satellite TV are each subject to a special set of laws and policies applying to them individually. The regulatory divisions thus established assume a clear demarcation between the services but break down when the same type of service is provided by different networks a phenomenon known as convergence. During the late 1980s and in the 1990s, mobile, fixed and satellite communications gradually began to converge, forcing the EU legislators to move towards a single regulatory framework. The chief challenge has been to address the technological convergence - the fact that one and the same service is provided by different networks. The 2002 Framework deals with the problem by abandoning the traditional telecommunications silo approach, where each type of service (fixed telephony, mobile telephony, and so on) is subject to a separate regulatory framework, and introduces a new one covering all 'electronic communication services'.

The modern phenomenon of convergence changed the picture again. While different networks historically used to provide distinct services, modern networks can deliver all services. The services are often packaged in groups of two, three or four, increasing their attraction to new consumers and decreasing the likelihood that old consumers will swap services (churn). All of this means that regulatory separation is slowly disappearing, which opens up the possibility for policies and laws to be 
drafted with the nature of the service provided in mind, rather than the now obsolete traditional division. On the other hand, the distinction between networks and services which run on these networks still exists, both in real life and in regulation. Multiple services can be provided on a single infrastructure (network). For example, a cable TV provider can deliver both TV/radio and high-speed Internet. A mobile network provides Internet access and mobile telephony, and may come with TV subscription or streaming services. This distinction has one very important consequence: increased competition between different networks. Since services are network independent and can be obtained on different networks, demand and supply-side substitutability is high.

The legal side of the question of regulation of EU telecommunications law is relatively straightforward: the subject of regulation is telecommunications networks and the services they provide. Both electronic networks and electronic services have specific EU definitions. ${ }^{11}$ Electronic networks comprise systems and equipment used for conveyance of signals by wire, radio or other means and include satellite, fixed and mobile networks. Electronic services comprise transmission and routing of signals on these networks as long as this is done for remuneration. The Framework Directive specifically emphasises that it does not apply to 'services providing, or exercising editorial control' over the content transmitted, nor to information society services, thus making a clear demarcation between the carrier layer, which is subject to telecommunications rules, and the content layer, which is not.

Article 2(c) of the Framework Directive defines 'electronic communications service' as 'a service normally provided for remuneration which consists wholly or mainly in the conveyance of signals on electronic communication networks'. Services and networks thus defined normally comprise the regulation of public switched telephone networks (PSTN), cable networks and mobile networks.

As will be further discussed in Chapter 2, there are three 'streams' of regulation in EU telecoms law: liberalisation, harmonisation and competition law. Liberalisation removes the power of former national monopolies; harmonisation brings national laws together; and competition law ensures that telecommunications markets and services are competitive. In a highly summarised manner, the core of the present EU ex ante regulation can be described as the application of competition law principles for market definition, the identification of operators with

11 See Article 2(a) and 2(c) of the Framework Directive. 
significant market power (SMP) and the imposition of regulatory remedies on these. While this core is significant, it would be a mistake to reduce EU regulation to it. The EU regulatory framework also deals with authorisation of telecoms operations, with consumer rights, with spectrum and with various aspects of NGN deployment.

Although the proposed European Electronic Communication Code (EECC) does not change the scope of regulation dramatically, Article 2(4) divides electronic communications services into three categories: Internet access services, interpersonal communications services (number dependent and number independent) and machine-to-machine (M2M) and broadcasting. Further to that, Recitals 16 and 17 EECC are concerned with a future-oriented definition of electronic communications services. Recital 16 points out that technical parameters should not be dominant but that a definition should rather build on a functional approach - functionally equivalent services ought to be covered by the same regulatory framework. The recital starts from the core activity that consists in the 'conveyance of signals' but includes all services that, from the end user's perspective, appear to perform the same function.

Recital 17 clarifies the monetary aspect of the services - the fact that a service needs to be provided for remuneration. The condition is also satisfied where services are supplied against the counterperformance, which may include personal data, irrespective of whether such data is supplied with the user's consent and knowledge or without it. The concept of remuneration should also encompass situations where the end user is exposed to advertisements as a condition for gaining access to the service.

The technology used for transmission of the signal plays a significant role in telecommunications regulation. Today, the signal can be transferred by radio, coaxial cable, optical fibre or 'twisted pair'. Copper cable has traditionally been the dominant medium but is gradually being replaced by fibre. While different types of network exist, a fundamental distinction between legacy networks and NGN can be made. Legacy networks can loosely be defined as any network not part of the modern TCP/IP protocol. In a legacy network, a wire going from the user's telephone connects to a local exchange, which is connected to a central exchange. Multiple signals can be combined for simultaneous transmission. A next-generation network, on the other hand, is digital. Signals are transformed into digital packets which are, in turn, transmitted according to a set of rules. ${ }^{12}$ It is important to note that the distinction

12 The TCP/IP protocol. 
between legacy and NGN is not inherent in the medium used to carry the signal. Older networks are made of copper but copper networks are capable of carrying digital signals. The International Telecommunications Union defines a next-generation network as:

a packet-based network able to provide services including Telecommunication Services and able to make use of multiple broadband, QoS-enabled transport technologies and in which service-related functions are independent from underlying transport-related technologies. It offers unrestricted access by users to different service providers. It supports generalised mobility which will allow consistent and ubiquitous provision of services to users. ${ }^{13}$

The EECC proposal uses the terms 'electronic communications network' and 'very high capacity network'. ${ }^{14}$ The former is a transmission system which may, but need not, be based on a permanent infrastructure, is based on signal routing, and permits conveyance of signals by 'wire, radio, optical or other electromagnetic means, including satellite networks, fixed ... and mobile terrestrial networks, electricity cable systems, ${ }^{15}$ networks for radio and TV broadcasting, and cable TV networks, irrespective of the nature of information conveyed'. Contrary to the 2009 model, the definition now emphasises that a transmission system need not be based on a permanent infrastructure. This brings various virtual networks under the scope of the law:

Very high capacity network is defined in EECC as a telecommunications network which either consists wholly of optical fibre elements at least up to the distribution point at the serving location or which is capable of delivering under usual peak-time conditions similar network performance in terms of available down- and uplink bandwidth, resilience, error-related parameters, and latency and its variation.

The division between legacy and NGN networks is important mostly because the legislator may decide to subject NGNs to more favourable rules in order to increase their deployment and takeup.

A particularly important aspect of telecommunications rules is the fact that they can be classified as services of general interest (SGEI) by national authorities. These are services which public authorities in Member States classify as being of special interest and therefore place

13 ITU: see http://www.itu.int/ITU-T/2001-2004/com13/ngn2004/working_ definition.html.

14 Article 2(1) and 2(2).

15 To the extent that they are used for the purposes of transmitting signals. 
under special public service obligations. These typically fall under three categories: economics, noneconomic and social. Article 106(2) TFEU is the basic constitutional provision on these services:

Undertakings entrusted with the operation of services of general economic interest or having the character of a revenue-producing monopoly shall be subject to the rules contained in the Treaties, in particular to the rules on competition, in so far as the application of such rules does not obstruct the performance, in law or in fact, of the particular tasks assigned to them. The development of trade must not be affected to such an extent as would be contrary to the interests of the Union.

The fact that a service is classified as SGEI puts it under the scope of the Commission's current package of laws, from 2011.16 Most of the obligations that relate specifically to telecommunications as SGEI have been implemented through various provisions concerning telecoms as universal services, although some aspects of SGEI have also been used in the debate on net neutrality.

\subsection{WHY REGULATE?}

The question of reasons for regulation is tightly connected to how networked industries in general (of which telecommunications is one) are regulated. ${ }^{17}$ The usual reason for intervening in networked industries is to bring consumer prices to a level close to those that would have been experienced had the market been fully competitive. Networked industries are subject to high costs, both fixed and sunk, and behave like natural monopolies. Regulation has traditionally had the task of ensuring some level of competition. The basic answer to the question in the world of telecommunications would be: regulation is needed to avoid market failure, increase competition, protect consumers and increase investment and overall welfare. Or, put in negative terms: where markets are failing, where the competition is inadequate, where users are not protected or

16 Communication from the Commission to the European Parliament, the Council, the European Economic and Social Committee and the Committee of the Regions - A Quality Framework for Services of General Interest in Europe, 20.12.2011, COM(2011) 900 final.

17 Networked industries can be defined in simplest terms as those industries which both depend on a set of connecting points and increase in value the more points there are in existence. Examples are computers, electricity, telecommunications, railroads, aviation, and so on. 
where existing technologies are used inefficiently and new technologies are not introduced, it is the regulator's role to step in and improve conditions. Successful regulatory reform in the mobile sector, for example, could increase mobile penetration and lower prices. A lack of reform, badly executed reform or badly implanted reform would, in turn, reduce choice and cause the prices to increase.

The lawmakers primarily strive to create a level playing field between the actors, usually by combining traditional competition law and ex ante regulation where the former is not suitable or cannot yet be applied effectively. They engage in regulating authorisation for operating networks and services. They control interconnection and access for the computing companies. They manage the spectrum upon which the wireless world depends. They make sure that everybody gets a basic level of service (universal access). They ensure a basic level of protection for end users. But the role the EU plays in telecoms regulation today was a result of very gradual changes, the history of which could well have turned out very differently.

The European Union began in the early 1950s as a customs and trade union for coal and steel. It transformed over the course of the 1960s and 1970s into a closer economic union. By the late 1980s, following an unprecedented drive to simplify legislation and create a closer economic union, a true Single Market had been created, with free movement of all factors of production, robust competition rules and various policies on matters ranging from agriculture to environmental protection and elements of foreign and security policy. Despite political ambitions, the EU remains a firmly economic union, inspired by economic aims, although guided by ideas of freedom and social justice. ${ }^{18}$ The idea of the Single Market refers to the EU as one territory, where goods, services, companies, people and capital can move freely as if it was one state. In order to achieve this, the EU needed to gradually remove barriers to trade, which, in turn, required Member States' laws to be brought closer together to produce the required standard. In earlier days, up to the late 1980s, the main strategy for this was full harmonisation of those laws which created disparities. From then on, this approach - which required difficult political compromises and resulted in watered-down proposals was gradually replaced with partial harmonisation. The new approach managed to streamline the process, leading to a much more integrated Single Market. The key to success was limited harmonisation, with the states relying on mutual recognition of each other's rules in cases where

\footnotetext{
18 See Article 3 TEU.
} 
there was no such harmonisation. In order to remove obstacles to free trade, it was necessary to harmonise different areas where these obstacles were apparent. In telecommunications, the obstacles to free movement of telecommunications services came in the shape of national monopolies. This, in turn, meant gradual removal of monopolistic power and gradual harmonisation, an endeavour hitherto not yet attempted.

Telecommunications was for the EU a difficult, albeit crucial, area. Like other key infrastructure (electricity, water, transport network, and so on), it was largely (albeit not exclusively) in the competence of the Member States. At the same time, it was mostly in public hands, usually with a single state monopoly in each Member State. The goal was to gradually break the national monopolies, increasing competition and lowering prices. This had to be achieved not through full harmonisation but first through gradual liberalisation - the breaking of the national monopolies - followed by a cautious introduction of common laws. This was the dominant approach through much of the 1980s and 1990s, with the first comprehensive telecommunications package coming only in 2002, well after liberalisation had been completed.

The transformation of telecommunications in the EU commenced in the 1980s with a set of changes that first began at the national level, ${ }^{19}$ and then spread to the EU. ${ }^{20}$ The changes began as liberalisation - a slow dismantling of national monopolies - and continued as a full move to a free-market system. In the UK, which was one of the EU countries that led the way, the national phone company was privatised and the local market opened to competition. This resulted in falling prices and increased investment. In the United States, the 1996 Telecommunications Act - a significant overhaul - promoted competition and reduced regulation. Inspired by these developments, the EU cautiously embarked on a project of telecommunications harmonisation that continued into the late 1990s.

Telecommunications were, until the mid-1980s, almost completely under national competence. ${ }^{21}$ State monopolies in both postal and telecommunications services existed in all Member States. Postal and

19 Jill Hills, Deregulating Telecoms: Competition and Control in the United States, Japan and Britain (Greenwood Press, Westport, Connecticut 1986).

20 Jacint Jordana (ed.), Governing Telecommunications and the New Information Society in Europe (Edward Elgar Publishing, Cheltenham 2002).

21 Thatcher suggests that early EU reform in this area may have been following national practices rather than leading them. See Mark Thatcher, 'The 
telecommunications services were controlled centrally and no independent regulatory bodies existed. In the 1970s a gradual change started to become apparent: technological convergence began to obliterate the lines that divided different telecommunications services, while further development of new technologies required investments on a large scale. ${ }^{22} \mathrm{At}$ the same time, the American model of decentralisation (see below) showed that alternatives were possible.

The Commission began the process of liberalisation in the 1980s, engaging in what can be described as deregulation or negative integration. ${ }^{23}$ Prompted by what it had seen in the United States, Japan and some EU states, the Commission was motivated by fear that Europe would fall behind if its telecoms market failed to adapt institutionally and structurally. The following years saw many changes, including the decoupling of postal and telecommunications services, privatisation, increased competition and new, more independent regulatory agencies. ${ }^{24}$ The EU competence to liberalise telecommunications that is today taken for granted had to be fought for. At first, the Commission's policy was in conflict with those of the Member States, some of which were reluctant to open up state-owned monopolies to competition. The matter was ultimately resolved with the (then) European Court of Justice's 1991 decision that the EU had the competence to regulate. ${ }^{25}$ The EU thus positioned itself at the centre not only as a liberaliser but also as a promoter of competition and user choice - a role which it maintains to this day.

Liberalisation on its own would not have been able to provide a fully competitive market. It was also necessary to harmonise disparate national laws. At first, the ambitions for this harmonisation seemed sufficiently high. In 1994, the Bangemann Report on Europe and the Global Information Society addressed the impact on Europe of the emerging

Commission and National Governments as Partners: EC Regulatory Expansion in Telecommunications 1979-2000' (2001) 8 Journal of European Public Policy 558-84.

22 See Mark Thatcher, 'The Relationship between National and European Regulation of Telecommunications' in Jordana (2002), pp. 66-85.

${ }^{23}$ On the differences between the two in EU policy see Maarten Vink, 'Negative and Positive Integration in European Immigration Policies' (2002) 6 European Integration Online Papers (EIoP) No. 13.

24 See Vokler Schneider, 'The Institutional Transformation of Telecommunications Between Europeanization and Globalization' in Jordana (2002), pp. 27-8.

25 See Chapter 3. 
information society and new technologies. ${ }^{26}$ The Report noted that there were 'entrenched positions which put Europe at a competitive disadvantage' and that action needed to be taken to foster entrepreneurship, develop new sectors of the economy and develop a 'a common regulatory approach to bring forth a competitive, Europe-wide market for information services'. For a while, it looked as if both telecommunications and information society services (ISS) would be subject to coordinated reform at this time, but eventually telecommunications were first, followed by ISS in the early 2000s. The discrepancy between the two remains to this day. The 2002 and 2009 reforms remained firmly grounded in the carrier field, and laws on ISS were developed independently. In spite of the lack of a single EU telecoms authority and the coexistence of EU and national telecoms laws, the reasons for EU intervention are as convincing today as they were in the 1980s. The question of reasons for regulation also needs to be looked at from the perspective of subsidiarity. In the simplest terms, the subsidiarity principle dictates that the EU should only intervene if it is in a better position to regulate than Member States are. In telecommunications the crossborder element is pronounced, and the existence of different policies in different states does make EU action justifiable.

\subsection{REGULATORY OBJECTIVES AND REGULATORY PRINCIPLES}

Regulatory objectives are targets or goals that legislation seeks to pursue in a situation involving intervention by an administration or a government. Regulatory principles, on the other hand, are the basic postulates or ideas which form the basis for such regulation or which inform it. Telecommunications has been subject to regulation by various EU administrations over the course of 30 years, ${ }^{27}$ and it is important both to understand which objectives the EU is guided by and which principles inform EU telecommunications policy. It is also important to determine whether a level of coherence exists between the declared objectives and the principles used to achieve them. It is equally important to determine

26 European Commission, Europe and the Global Information Society: Recommendations to the European Council and the European Commission, Brussels, 26 May 1994.

27 There have been five different Commission setups with five different policy agendas since 1987, when the first comprehensive policy on telecommunications was formulated. 
whether different reforms of telecommunications law have pursued the same objectives methodically and consistently, and whether they need to be modified in light of the developments of the subject matter regulated. Finally, the coherence and efficacy of regulatory objectives can be, and regularly are, challenged by various stakeholders.

Formulating regulatory objectives and principles in the EU has proved challenging, since telecoms did not initially fall squarely within any EU regulatory competence. This meant that the regulatory objectives had to be set less ambitiously, since it was not certain that the more ambitious ones would successfully be adopted. For example, in explanatory notes for each of the succeeding regulatory reforms, a note is made to the effect that having a single EU telecoms regulator would be desirable but is difficult or impossible to achieve at this stage. In spite of this, a relatively coherent set of objectives and principles forms the basis for EU telecoms regulation.

\subsubsection{Regulatory Objectives}

The EU regulatory objectives were spelled out relatively clearly from the earliest days of the reform. In tracing the documents, one can notice three clear goals in all regulatory frameworks. ${ }^{28}$ The first is the desire to boost the development of infrastructure. In more recent years, this has shifted to investment in next-generation networks, high-speed Internet and 5G wireless. The second is the desire to protect consumers/end users. The third is to improve coordination between EU bodies and national authorities and to reach more effective enforcement of EU rules.

The early documents had sector-specific goals in their focus, only occasionally (and vaguely) referring to wider intentions. The Commission was significantly more specific about the purposes of the 2002 reform, however. The EU legislation was still to be sector-specific but the Framework Directive identified the general and specific policy objectives, and was accompanied by four specific directives on authorisation, access and interconnection, universal service and privacy and data protection, all of which pursued the same unified set of goals. The overall aim of such a structure was a simplification of the pre-2002 framework, the reduction of the number of legal measures and the increase of focus. In addition to the basic framework, there would also be nonbinding accompanying

28 Pre-2002, 2002, 2009 and draft 2016. 
measures. Finally, there would be greater reliance on the general competition rules in the Treaty, with the ultimate aim of replacing sectorspecific regulation with effective competition rules. In such a setup, investment, protection of competition, development of the internal market and protection of EU citizens' interests were the four primary objectives. $^{29}$ The 2009 reform had kept the basic thrust of the 2002 reform but sharpened some of the objectives. One of the changes brought about was the desire to protect net neutrality. ${ }^{30}$ Another was to increase consumer protection and improve data protection.

Article 8 of the Framework Directive, one of the most important articles in the current Regulatory Framework, clearly spells out both policy objectives and policy principles. Three regulatory objectives exist in the present framework. They are set out in paragraphs 2, 3 and 4 of the Article. Article 8(2) concentrates on promotion of competition, which has been the primary aim of the liberalisation stream of EU legislation. ${ }^{31}$ This includes rules on choice, price and quality for all users, lack of distortion or restriction of competition and efficient use and management of radio frequencies. Article 8(3) concentrates on harmonisation, requiring promotion of the internal market by removing obstacles to the provision of telecoms services, by promoting the establishment and development of trans-European networks and capacities and by Commission and BEREC cooperating with each other. Finally, Article 8(4) is about the protection of citizens' interests. This is to be done through ensuring universal service, simple dispute resolution mechanisms for disputes between suppliers and consumers, high data protection standards, clear information, protection of vulnerable groups, protecting cybersecurity and protecting the ability of end users to freely distribute information and run applications of their choice. Cultural and linguistic diversity as well as media pluralism are listed in Article 8(1) as optional regulatory objectives, to be pursued at the discretion of NRAs. It seems that some objectives that exist at national level in some Member States could be easily added to the ones already pursued in the EU. Primary

29 This is only slightly different from the content layer directives, which talk mainly about the internal market and consumers.

30 In detail on this, see Chapter 10.

31 On liberalisation and harmonisation as two distinct approaches, see Chapter 3. 
among these should be the ability the promote innovation. To this could probably be added the protection of fundamental rights and public interests. $^{32}$

The EECC proposal brings new objectives in the form of incentivisation of investment in high-speed broadband networks, ${ }^{33}$ a more consistent single market approach to spectrum policy, removal of regulatory fragmentation and a level playing field for all players. Article 3(2) EECC reformulates the objectives of the 2009 framework as development and takeup of very high capacity data connectivity, promotion of competition, development of the internal market and promotion of citizens' interests.

\subsubsection{Regulatory Principles}

The '1999 Review' Document, ${ }^{34}$ which introduced the 2002 Telecoms package and thus spearheaded the most comprehensive telecommunications reform in the EU, was centred on five regulatory principles: ${ }^{35}$

- Legislation ought to be based on clearly defined policy objectives.

- Legislation ought to be the minimum necessary to meet those objectives. Where competition can achieve the policy objectives previously reserved for sector-specific regulation, this should be the preferred option.

- Legal certainty needs to be enhanced further.

- Legislation needs to be technologically neutral. Same services ought to be regulated in the same manner, irrespective of what technology is used to deliver them.

- The enforcement ought to be closely related to the activities being regulated.

Framework Directive Article 8(5) specifically lists six regulatory guiding principles. These are meant to inform the principles which NRAs themselves are developing in pursuit of the regulatory objectives listed in

32 Cf. Matthias Finger et al., FSR Manifesto: An EU Agenda for the Upcoming Five Years of Regulation of Infrastructures (European University Institute, 2015).

33 See Recital 3.

34 Communication from the Commission to the Council, the European Parliament, the Economic and Social Committee and the Committee of the Regions of 10 November 1999, Towards a New Framework for Electronic Communications Infrastructure and Associated Services - The 1999 Communications Review, COM(1999) 539 final.

35 On the historical development of these principles, see Section 2.2.1. 
Article 8. These guiding principles are meant to be objective, transparent, nondiscriminatory and proportionate. In particular, the Article adds, they must:

- promote regulatory predictability by acting consistently and with appropriate review periods;

- ensure that there is no discrimination in the treatment of undertakings providing telecoms networks and services in similar circumstances. This idea, which can also be found in the Commission's preparatory documents, is that like services should be regulated alike; 36

- safeguard competition to the benefit of consumers and promote infrastructure competition;

- promote efficient investment and innovation in new and enhanced infrastructures. This includes the obligation that any access remedies take into consideration the risk incurred (since telecommunications investment are high-risk ventures) and that risk diversification measures are permitted;

- take account of different conditions relating to consumers and competition that exist in different Member States;

- only use ex ante regulation where competition is not functioning properly. This is a consequence of the Commission's early decision to initially use ex ante, sector-specific regulation, with a gradual transition to competition rules in later stages.

In addition to the principles declared in the 2002 and 2009 reforms, since the beginning of the EU's interest in telecommunications there has been a set of what can best be described as regulatory approaches which have been particularly relevant for telecommunications and IT regulation. Several are of importance.

First, the Commission uses technological neutrality as a principle. ${ }^{37}$ The principle, which is clearly spelled out in Article 8(1) and in other documents, simply means that regulation should not be written around any particular technology but should be adaptable. This is particularly important since early telecommunications laws were technology-specific.

36 This has become particularly important in recent times, with the Commission considering whether OTT services, which are not telecommunications services but are competing as such, should be subject to telecoms rules.

37 This is different from net neutrality, which is not a regulatory principle but a policy choice. See Chapter 10. 
Second, the 2002 Framework introduces the principle of the separation of regulatory and operational functions. ${ }^{38}$ This means that NRAs ought to be independent from national telecoms operators so as to ensure their impartiality.

Third, the general EU principle of subsidiarity obliges EU to act only when it, not the Member States, is better suited to the task. This principle also has a more general aspect, which can be called regulatory restraint a need to regulate only when this is necessary. An example of regulatory restraint is found in guidelines on the market analysis and the assessment of SMP which advise NRAs not to subject market leaders in the emerging markets to 'inappropriate ex ante regulation'. ${ }^{39}$ In this case, the market leader is likely to have a significant market share but premature intervention might influence the competitive situation in a negative way.

In 2015, the Commission published the EU Better Regulation Guidelines, ${ }^{40}$ aiming at improving the fulfilment of objectives pursued by EU laws and getting better regulation more efficiently and at a lower price. A key element of the new strategy is fitness checks, which are regular reviews of legislation with comprehensive input from stakeholders. These reviews would ensure that legislation could be corrected and tailored to fulfil the declared aims. While the telecoms refit process had an impact on a number of issues, it left the basic objectives and principles largely intact.

The EECC does not fundamentally change the principles that should be used in pursuing the regulatory objectives, although safeguarding competition is deleted as a principle, ${ }^{41}$ and technical neutrality officially elevated to principle level. Another change relates to infrastructure, which is added to the list of items which need to be looked at from a geographic perspective (including competition and consumers).

\subsection{ECONOMIC PRINCIPLES}

Telecommunications is subject to a number of economic principles specific to networked industries. Today, network economics presents some peculiar issues, knowledge of which is crucial for an understanding

\footnotetext{
38 See Framework Directive, Preamble 11.

39 OJ C 165/6, 11.7.2002.

40 Commission Staff Working Document, 19.5.2015 SWD(2015) 111 final. Available at http://ec.europa.eu/smart-regulation/guidelines/toc_guide_en.htm.

41 Since it is an overarching theme in the regulatory framework and a separate regulatory objective.
} 
of how telecommunications operate. At the basic level, the economic issues relate to access service providers (access pricing models), economics at the content and application level and interactions and relations between network providers and content and application providers. ${ }^{42}$ Understanding the basic economic principles behind telecommunications is necessary not only for writing good telecommunications laws but also in order to understand why some of these laws are failing.

One of the most important issues in telecommunications has been the question whether telecoms are a natural monopoly. How this question is answered affects the choice of regulatory model applied to them. Economically, a natural monopoly occurs where the most efficient number of firms in an industry is one. It is a monopoly where an advantage over competitors is given to a firm (often the first in the market) due to high fixed or startup costs or other barriers to entry. For several decades in the first half of the twentieth century, a dominant view was that telecommunications is a natural monopoly and that nothing will be gained from competition in the sector. In order to achieve efficiencies and maintain positive network externalities, it was necessary to have one single firm. In exchange for this peculiar kind of government protection, it was necessary to apply regulation to keep prices fair, and in a vast majority of cases, the entity was simply state owned. The Commission has shown a certain degree of tolerance towards natural monopolies in networked industries, normally requiring that they demonstrate that they treat other companies fairly, make their infrastructure available to all users and not use the profits made by providing a public service to subsidise commercial operations. This state of natural monopoly has gradually given way to various liberalisation attempts, followed by access regulation. ${ }^{43}$

Modern governments are not normally capable of investing in and maintaining telecommunications services and require the private sector to do the job. The incumbent monopolist is rarely incentivised to do the job itself and is sometimes not capable of it. This, in turn, has led to regulators relying on liberalisation, which, in the simplest terms, can be described as the removal of government intervention in a particular sector. Since a government cannot be relied upon to invest in, operate and maintain telecoms, the markets should be liberalised to allow the private

42 See in general Patrick Maillé and Bruno Tuffin, Telecommunication Network Economics: From Theory to Applications (Cambridge University Press, Cambridge 2014).

43 For the EU, see Chapter 2. 
sector to do so. ${ }^{44}$ Liberalisation has thus been the dominant form of regulation in the second half of the twentieth century both in the United States and in Europe. This is not surprising. Telecommunications are characterised by high barriers to entry, that is, entry costs are prohibitively high. Markets are dominated by the incumbents, who have to be forced to open up resources so that their competitors can reach end users. Liberalisation of the telecoms markets required the use of competition law. But competition law is not inherently suited for successful liberalisation:45 it is meant to target abuses after they happen, it operates on a case-by-case basis and it requires monitoring and enforcement procedures that can stretch over years. Instead of this, it was opportune to use a combination of ex ante rules, that would increase prevention, and ex post remedies. This would lead to greater legal certainty and more flexible enforcement. ${ }^{46}$

At a very basic level, two economic principles are fundamental for the understanding of telecommunication economics. ${ }^{47}$ Network effects refers to the phenomenon where a good or a service gains in value for each individual user as its general usage base increases. A simple example could be that of a new social network which starts off with a few enthusiasts but quickly gains new followers. The network initially has some value for its early adopters but this value keeps increasing for each added subscriber. For the majority of its history, telecommunications was represented by PSTN and legislators' efforts concentrated on forcing the more or less dominant companies to share their customer bases. The historical importance of network effects lies in the fact that much of

44 On the economics of telecoms liberalisation see Kjell A. Eliassen and Marit Sjovaag Nfa (eds), European Telecommunications Liberalisation (Routledge, Abingdon 1999).

45 On remedies in network industries from this perceptive see Damien Geradin and Gregory J. Sidak, 'European and American Approaches to Antitrust Remedies and the Institutional Design of Regulation in Telecommunications' in Sumit K. Majumdar, Ingo Vogelsang and Martin E. Cave (eds), Handbook of Telecommunications Economics, Vol. 2 (Elsevier BV, Amsterdam 2005), pp. 517-53.

46 On the balance between ex ante and ex post regulation and the plans to ultimately move to competition law only, see Chapter 4.

47 See Jonathan E. Nuechterlein and Philip J. Weisser, Digital Crossroads: Telecommunications Law and Policy in the Internet Age (The MIT Press, Cambridge, Massachusetts 2013), pp.3-17. In terms of pricing, the question poses itself in the form of price controls. See Christopher Decker, Modern Economic Regulation: An Introduction to Theory and Practice (Cambridge University Press, Cambridge 2015), chapters 5 and 10. 
twentieth-century legislation was about forcing the independent telephone companies to interconnect with each other. Here, network effects play a significant role where the legislator decides to make a useful service even more useful. In order to increase network effects (increase the value of their connection to each consumer), lawmakers have forced telephone companies to interconnect. ${ }^{48}$ The existence of network effects in the telecommunications industry also puts pressure on resources. High demand for content in services where network effects exist (for example, social networks) puts pressure on the available resources, creating demands on legislators to intervene. While interconnection between PSTNs has been subject to extensive regulation, that between data providers has not. Companies providing Internet services traditionally enter into peering arrangements for data exchange. No regulation has been necessary here. ${ }^{49}$

Economies of scale are the cost advantages that companies achieve due to their size. ${ }^{50}$ In telecommunications, the term refers to the fact that telecommunications providers that have a large customer pool achieve significant savings. Telecommunications often involves largescale investments (laying cables, setting up satellite networks or acquiring other equipment). A telecoms provider would, in principle, be interested in achieving those economies of scale. Where this is not possible, a provider is disincentivised from investing in the new technology. Economies of scale are of particular importance in the telecommunications world since many telecommunications companies have historically been considered

48 In the USA, this happened gradually, beginning in the early twentieth century. In Europe, inter-EU interconnections were introduced in Commission Directive 90/387/EEC of 28 June 1990 on the establishment of the internal market for telecommunications services through the implementation of open network provision, OJ L192/1 (ONP Framework Directive).

49 On this issue in the context of net neutrality and why net neutrality is not applicable here, see Chapter 10.

50 A related concept - economies of scope - is the idea that the average total cost of production decreases as a result of increasing the number of different goods produced. In other words, economies of scope exist where a firm can produce two different kinds of a product at a lower per-unit cost than would have been the case with only one. Economies of scope are important in telecoms as firms delivering both voice and data or both data and TV are in a better position to attract customers. For evidence in US telecoms, see Rajiv Bankera, Hsi-Hui Chang and Sumit Majumdar, 'Economies of Scope in the U.S. Telecommunications Industry' (1998) 10 Information Economics and Policy 253-72. Another related concept, economies of density, relates to cost savings which can be had from close proximity of suppliers and providers. 
to be natural monopolies. ${ }^{51}$ Since the regulators considered telecoms companies to be in a natural position of dominance, they have traditionally been reluctant to break them up. In Europe, significant efforts in this direction were only undertaken in the late 1980s. The reluctance to intervene was also led by another interest: natural monopolists were obliged to provide universal service - packages of basic telecoms services that everybody had the right to. Since this was infinitely easier to impose on the monopolist (an example might be an obligation to connect a remote village where it would normally not make economic sense to do so) than on a competitive provider, the regulators usually did not intervene. ${ }^{52}$ Economies of scale are made easier for competitors by the emergence of new technologies which allow them to provide the same or similar services with only a fraction of the investment required.

Telecoms are characterised by high entry barriers. ${ }^{53}$ Gaining entry requires either very high capital expenditure - a factor favouring legacy monopolies - or innovative products. The biggest barrier to entry seems to be access to finance. The requirement of any kind of authorisation also acts as a barrier to entry, as does scarcity (in spectrum, for example). High barriers to entry, as a rule, increase the likelihood of regulatory intervention. In the EU, the presence of high and nontransitory structural, legal or regulatory barriers to entry has been taken as a sign that a particular market is susceptible to ex ante regulation. ${ }^{54}$ Entry can be deterred by other factors, such as absolute cost advantages or capacity constraints.

The ladder of investment is a regulatory principle used in network industries that determines the desired relationship between regulation and type of competition. Its aim is to encourage investment by both the incumbents and the new entrants by creating a progression from accessbased competition (where the incumbent's facilities are leased) to service-based competition (where new entrants build their own infrastructure). The principle is a result of the fact that competition in the telecommunications sector can be brought about by entrants building their own infrastructure (cables, transmission stations, and so on) or by

51 A natural monopoly exists where the largest supplier can serve the market with a lower overall cost than other firms.

52 In the US, the natural monopoly idea was only truly abandoned in the 1996 Telecommunications Act. See Section 1.6.

53 Not to be confused with high sunk costs, which are costs that have already been incurred - an investment that a firm puts at risk and cannot retrieve and which also acts as a barrier to entry.

54 See Chapter 4. 
leasing access to incumbents' facilities. The former is referred to as facilities-based competition and the latter as service-based competition. In principle, only the former is capable of promoting innovation in the long term. The 'ladder of investment' idea is based on the assumption that service-based competition will provide the entrants a customer base and a foot on the 'ladder' but that they will subsequently invest in the infrastructure themselves. Regulation that follows the 'ladder' approach, therefore, aims first to open up access and interconnect markets and then to encourage investment into infrastructure. ${ }^{55}$

The idea, as suggested by Cave in $2003,{ }^{56}$ is that initially low access prices for all network services are to be followed by rising prices applying successively to assets in descending order of replicability. Entrants begin by replicating the assets which are easiest to replicate but need access to those which are not. In this way, the new entrants will be encouraged to invest gradually while the incumbents' incentive to invest will not be removed. The EU adopted the ladder of investment from 2003. At present, there is debate as to the effectiveness of the approach in delivering increasingly higher levels of investment. There are signs that the approach, which was adequate at the time when the priority was to make access to already existing infrastructure easier, is no longer able to sustain a level of investment in next-generation networks. ${ }^{57}$ The EU-chosen approach - of regulating access as opposed to incentivising investment - involves a tradeoff. ${ }^{58} \mathrm{~A}$ sustained investment level depends on the profit margins that are in turn possible in a situation where optimum competition intensity exists. Empirical evidence exists today to confirm that 'the more service-based competition is pronounced the more negative is the impact on NGA deployment' ${ }^{59}$ Evidence today suggests

55 See Martin Cave, 'The Ladder of Investment in Europe, in Retrospect and Prospect' (2014) 38 Telecommunications Policy 8-9, 674-83.

56 Martin Cave and Ingo Vogelsang, 'How Access Pricing and Entry Interact' (2003) 27 Telecommunications Policy 717-28.

57 See Wolfgang Briglauer, Carlo Cambini and Michał Grajek, Why Is Europe Lagging on Next Generation Access Networks? Bruegel Policy Contribution 2015/14, available at http://hdl.handle.net/10419/126691.

58 See Michał Grajek and Lars-Hendrik Röller, 'Regulation and Investment in Network Industries: Evidence from European Telecoms', (2012) 55 Journal of Law \& Economics 1, 189-216.

59 Wolfgang Briglauer, Georg Ecker and Klaus Gugler, 'The Impact of Infrastructure and Service-Based Competition on the Deployment of Next Generation Access Networks: Recent Evidence from the European Member States' (2012) 25 Information Economics and Policy 3, 142-53. 
that access regulation may lead to an overall loss as service-based competition does not lead to facility-based entry.

\subsection{TELECOMS REGULATION IN THE UNITED STATES AND ITS INFLUENCE ON EUROPE}

The history of telecommunications regulation in the United States is important for understanding EU telecoms, for several key reasons. ${ }^{60}$ First, the United States was a leader in developing the various technologies that stand behind telephone, television and the Internet. Understanding the regulation of these technologies properly often means understanding their American origins, their development and the historic regulatory choices made in the United States. Second, the United States leads the world in the provision of both telecommunications services and Internet content, with business models frequently originating in the United States or, as is the case with the World Wide Web, being partially based there. Regulation on one side of the Atlantic therefore often has direct consequences on the other. Third, European legislators frequently use regulatory models that are influenced by American ones. ${ }^{61}$ Fourth, the observation of different policy paths can lead to better understanding of the results they produce, as the United States has taken different regulatory choices in a number of key areas. ${ }^{62}$

In spite of any seeming similarities, however, it is equally important to understand that American and European markets function in very different ways. For the purposes of telecommunications, the United States is a single telecommunications market, whereas the European Union consists of 28 separate Member States. Issues such as authorisation and interconnection, while harmonised to some extent, remain in the domain of the Member States. The United States is dominated by a small number of very large telecommunications operators and is, by and large, less competitive than the EU. ${ }^{63}$ The United States and the EU entrust different

\footnotetext{
60 For an overview see Neuchterlein and Weiser (2013).

61 For examples of this, see Chapter 4 on competition and Chapter 10 on net neutrality.

62 For how broadband unbundling policies diverge and the consequences this has had, see Martin H. Thelle and Bruno Basalisco, How Europe Can Catch Up With the US: A Contrast of Two Contrary Broadband Models (Copenhagen Economics, paper, 2013). For net neutrality, see Chapter 10.

63 It is also somewhat more advanced in terms of $4 \mathrm{G}$ mobile coverage and takeup.
} 
agencies with the development and oversight of telecommunications policies. The political processes, including lobbying, that influence telecoms regulation differ too. All of this should serve as a warning against applying similar regulatory solutions to dissimilar situations.

The United States has had a troubled but exciting history of essential infrastructure regulation. The gradual development of railroad monopolies at the end of the nineteenth and the beginning of the twentieth centuries has led to the creation and application of competition rules and new regulatory agencies. ${ }^{64}$ For most of the twentieth century, wired telecommunications had the status of a natural monopoly, ${ }^{65}$ held by AT\&T, which was only gradually eroded through various liberalisation measures that affected equipment and local and long-distance lines. Here, the government attempted to encourage other firms to enter the market and begin competing with the dominant AT\&T, both by offering longdistance services and building their own infrastructure. The government intervened during that time to ensure that dominance in the local telephone market would not translate into anticompetitive behaviour in the adjacent wired telecoms services.

The 1934 Communications Act was a codification of a number of acts that applied to different aspects of telecommunications. ${ }^{66}$ One of the main aims was to create a single regulator who would be in charge of enforcing all telecommunications laws, present and future. It replaced the Federal Radio Commission with the Federal Communications Commission (FCC). A crucial innovation comes from the Act's classification of telephone companies as common carriers. ${ }^{67}$ Since common carriers perform a public function, they are subject to special regulation (authorisation, operation, privacy, and so on). This meant that telecommunications remained regulated for the better part of the twentieth century. Whether a service should be subject to common carriage rules or not may have significant consequences, since this normally means more regulation

64 On parallels between railroad regulation and telecommunications, see Susan Crawford, Captive Audience (Yale University Press, New Haven 2013), chapter 1. On the consequences of industrial consolidation in legacy technologies, see Tim Wu, The Master Switch: The Rise and Fall of Information Empires (Knopf, New York 2010).

65 See Section 1.5.

6648 Stat. 1064.

67 A common carrier is an entity that provides wired and wireless telecoms services to the general public (usually against payment). This is as opposed to contract carriers which only provide such services to a limited number of customers. 
and more oversight - a question which was acutely opened with the net neutrality debate. ${ }^{68}$

Although telecommunications started from the position of a monopoly, technological changes and the gradual removal of barriers to market entry also led to deregulation in the 1970s and 1980s. The monopolist AT\&T had been split up into seven independent companies in 1984, with AT\&T retaining its long-distance network but with regional traffic being broken up into seven monopolies. The long-distance market had since become competitive. When the Internet started emerging in the 1990s, it had largely remained unregulated.

The 1996 Telecommunications Act was, essentially, the only modern codification of telecommunications law in the United States. ${ }^{69}$ The Act was an attempt to increase competition in all telecommunications markets and allow anyone to enter the telecommunication business without obstacles. It brought significant changes, such as the ability of the FCC to preempt state legislation presenting barriers to entry, new rules on interconnection to incumbents' networks (the 'unbundled networks elements' policy, or UNU) and regional Bells'70 ability to enter the longdistance market in exchange for opening up access to their network. ${ }^{71}$ In addition to interconnection, the Act introduced unbundling and leasing of unbundled elements, various access conditions and nondiscrimination.

The first three titles of the Act are each devoted to one specific kind of telecommunications services. Title I applies to telecommunications carriers, Title II to broadcast services and Title III to cable. The titles use different regulatory models. Telecommunications policy in the United States addresses telephone, wired, cable and satellite communications, as well as radio frequencies. The regulatory model is based on competition law with specific elements of ex ante regulation. One important aspect of US telecoms laws is that telecoms companies are regulated as common carriers, ${ }^{72}$ placing them under Title II of the 1996 Act. Title II, which dates back to 1934, had originally been introduced to ban 'unjust or unreasonable discrimination' in providing phone services. As a rule, it

68 The FCC's recent reclassification of ISPs as common carriers was contentious in the net neutrality debate in the US. See Section 10.2.

69110 Stat. 56.

70 Companies that came into existence after AT\&T's breakup.

71 At this stage, the regional Bells (RBOCs) were entitled to enter the long-distance market while their own local loops were subject to unbundling.

72 Common carriers are required, by law, to provide services to all who demand them and are held to certain standards of care, but have liability limited to incidental damage. 
provides for more control and tighter regulation (including regulating access conditions and price regulation in Section 201) than Title III (cable). ${ }^{73}$ Significantly, the Internet, which in 1996 was only in its early stages, was not placed under Title II. In the view of some, this had both enabled it to prosper under a regulation-free environment and created a potential problem for cases where regulatory intervention was needed to prevent anticompetitive behaviour.

The FCC of today is an independent governmental agency in charge of regulating all interstate wired and wireless, as well as satellite and cable, communications. The agency was originally formed under the 1934 Act. While its structure is somewhat complex, the agency is directed by five commissioners appointed by the president and it coordinates policy in broadband, cable and satellite, radio, TV, content regulation and media ownership.

Like those elsewhere in the world, American policymakers face dilemmas concerning the adequacy of the old regulatory framework for the digital age. These can be tentatively grouped into three questions. First, similar services can today be provided by very different technologies, and the question is how the regulator ought to respond to that convergence. The basic premises of the regulatory framework date to 1934, a time long before convergence, and the framework's adequacy remains an issue. The second question concerns the best strategy for promoting modern wired (very high speed) and wireless (5G) technologies. This question is tightly connected to that of whether the regulator ought to encourage building of the new infrastructure as opposed to enabling access to the incumbents' assets. The third question concerns the regulatory and institutional setup best suited for IP-based telecommunications. As shall be seen in the chapters to follow, European lawmakers struggle with similar issues.

\subsection{REGULATORY APPROACH IN THE EU}

We saw in Section 1.3 what the basic motives for EU regulation were, and we have observed the principles on which the legislation has been formed. The success of a regulatory effort, however, depends on different elements. ${ }^{74} \mathrm{~A}$ regulator which is structurally and financially independent

73 This has become very significant since broadband's reclassification as Title II in 2015. See Section 10.2.2.

74 See Telecommunications Regulation Handbook (10th edition, IBRD, The World Bank, InfoDev, ITU 2011), pp. 14-21. 
will perform significantly better than one which is not. Some organisational approaches to regulation work better than others. A choice of regulatory objectives and regulatory principles would also determine the measure of an effort's success. ${ }^{75}$ But, in any case, the choice of EU regulatory tools and their deployment has been a result of a number of influential factors.

Possibly the most important feature to have influenced EU telecoms regulation is technological convergence, which, it will be recalled, means that the same service can be provided by different technologies (voice over Internet, broadband over cable, and so on). One major consequence of the reality of convergence is that it no longer makes sense to have different laws for different technologies or platforms where all of them provide the same service. While some aspects of this difficulty have been solved through the technological neutrality principle already used in modern telecoms legislation, ${ }^{76}$ this only partially solves the problem. First, while interplatform competition (competition between different technical means of providing voice or broadband) is a desired goal, it is not yet a fully realised reality. Although mobile technology has replaced fixed voice in many instances, mobile data still lags behind wired access. Likewise, while community antenna television (CATV) is capable of providing broadband (and does so in, in some cases, up to a quarter of all households), it is not a viable competitor everywhere. All of this means that it sometimes does make sense to regulate different technologies differently, to increase their attractiveness and thus improve competition. Second, even within one regulatory framework, flexibilities exist in terms of how much regulation is imposed. This is apparent both in the 2009 framework and in the proposed EECC. Technological convergence forces the regulator to think in a flexible manner and keep both intraplatform and interplatform competition in focus.

One of the main features of telecommunications regulation is its Single Market character. Telecoms laws in their present form can be described as an attempt to achieve a single market for telecommunications networks and services in the EU. Unlike many other aspects of the Single Market, such as free movement of goods and services, which resulted from a few general Treaty provisions being developed by the Court, EU telecoms regulation is a result of detailed rules in the form of directives, regulations, decisions and other secondary laws. These rules provide a

\footnotetext{
75 See Section 1.4.

76 Which means that different technologies are subject to the same framework.
} 
general regulatory framework, which is then put into practice not by a centralised EU agency charged with telecoms regulation, but by national regulatory bodies. These bodies are empowered to act on their own, with a duty to cooperate between themselves and with EU organs.

The second main feature of the regulatory framework is that it is based on competition law. As will be further explored in Chapter 4, the EU uses a combination of a traditional competition law approach and sectorspecific regulation. ${ }^{77}$ While the former means that competition authorities evaluate whether competition had been violated ex post, that is, after the potential violation has happened, the latter means that regulation allows competent authorities to impose remedies ex ante, that is, in anticipation of a potential violation and with a view to preventing it. Sector-specific, or ex ante, regulation is today used in combination with competition law and, as will be discussed in Chapter 4, in anticipation of the latter eventually replacing the former. This dual system arose from the need to have a more flexible regulatory system than competition law in a situation where a starting position is a monopolistic or an oligopolistic market.

One of the key ideas in telecommunications regulation tied to the existence of ex ante regulation is the distinction between asymmetric and symmetric regulation. Symmetric regulation applies equally to all network and service providers, irrespective of their historic status (incumbent or not), size, economic power, and so on. Asymmetric regulation applies only to some carriers (usually the incumbents). Traditionally, telecoms regulation has been asymmetric, since the idea is to make the playing field level, that is, to enable new entrants without economic power or a user base to compete on similar grounds as the incumbents. Most of EU telecommunications regulation, including the EECC proposal, is asymmetric. The prudence of insisting on this type of regulation is questioned today in light of the need to deploy fibre and 5G wireless quickly and to a large number of users. Shortall and Cave have observed two regulatory approaches which have been used in EU countries in this respect. ${ }^{78}$ Whereas France, Spain and Portugal opted for an infrastructure-based approach, which has also been the Commission's initial position on NGN, Belgium, Germany and the UK preferred the Commission's compromise approach, which calls for upgrading copper.

77 See Joaquín Almunia, 'Competition v Regulation: Where Do the Roles of Sector Specific and Competition Regulators Begin and End?' SPEECH/10/121, 23.3.2010.

78 See Tony Shortall and Martin Cave, 'Is Symmetric Access Regulation a Policy Choice?' (2015) 98 Digiworld Economic Journal 17. 
Shortall and Cave point out that, whereas both approaches lead to NGN deployment, only the former, infrastructure-based one builds a proper basis for symmetric regulation. Asymmetric regulation is in this respect regulator-dependent, that is, it is maintained as long as the regulator wishes it to be.

Third, there are two different forms of competition that are relevant for the telecommunications sector: service- and infrastructure-based competition. In the service-based competition model, the regulator encourages the entrant to offer competitive services through asymmetrically imposed access regulation on undertakings with significant market power (usually on incumbents) without rolling out their own infrastructure. ${ }^{79}$ This is a system in which access to incumbents' network is made available and pricing for that access is regulated. The access may be physical access to downstream infrastructure or virtual access, where access is provided virtually by the owner of the infrastructure. In the infrastructure-based model, the competitors are incentivised to build their own infrastructure. This approach is recognised as significantly riskier, 80 but is also the only one that can lead to long-term competition, as has been recognised in both the present and future regulatory frameworks. Furthermore, empirical research suggests that only infrastructure-based competition is capable of delivering NGN and that access regulation may have a negative effect on both total industry and individual carrier investment. ${ }^{81}$

Another idea closely connected with the above is the already mentioned 'ladder of investment' ${ }^{82}$ This is the notion that both the incumbents and the new entrants to the market can be made to invest, with the latter encouraged through gradual access regulation. The ladder is a

79 For the empirical evidence regarding the relative benefits of each approach in the EU in the first part of the 2000s, see Jörg Lundborg, Martin Lundborg and Ernst-Olav Lundborg, 'Infrastructure-Based Versus Service-Based Competition In Telecommunications', MPRA Paper No. 3571, 14 June 2007. For more recent evidence see Wolfgang Briglauer, Klaus Guglerb and Adhurim Haxhimusab, 'Facility- and Service-Based Competition and Investment in Fixed Broadband Networks: Lessons from a Decade of Access Regulations in the European Union Member States' (2016) 40 Telecommunications Policy 729-42.

80 See Section 1.5.

81 Michał Grajek and Lars-Hendrik Röller, 'Regulation and Investment in Network Industries: Evidence from European Telecoms' (2012) 55 Journal of Law \& Economics 189-216. See also WIK Consult, Deloitte, IDATE, Regulatory, in Particular Access, Regimes for Network Investment Models in Europe, Final Report, September 2016.

82 See Section 1.5. 
regulatory approach in that regulation is tailored to enable new entrants access in the hope that they will gradually invest in infrastructure as they gain a customer base. At the same time, incumbents are not discouraged from investing as access conditions are not meant to completely deprive them of a customer base. ${ }^{83}$ The fear, however, has long been that encouraging access-based competition comes at the price of reduced incentives to investment and ensuring sustainable competition. The approach adopted in most of the Member States has been a ladder of access options, with an expected increase in infrastructure investment by new entrants. This, in theory, leads to short-term competition gains, with long-term competition ensured through infrastructure investment. The evidence, however, demonstrates that access-based competition, on which EU regulation is largely based, is capable of delivering a shift from resale to bitstream, but not a move to investment in fixed infrastructure. ${ }^{84}$

Finally, although the EU telecommunications regulation is a Single Market-based, competition-oriented system, which mostly targets enterprise operations at the wholesale level, it also brings consumer protection at the retail level and introduces privacy protection for both individuals and enterprises. ${ }^{85}$ The SMP ex ante Regulatory Framework of 2002 has gradually eliminated regulation at the retail level, save for consumers and end-user protection measures. The dominant model today is to use wholesale regulation to solve problems at the retail level. This presents difficulties, as several wholesale markets can supply inputs to one retail level or, conversely, one wholesale market can supply several retail levels. The 2016 Proposal is also aware of the decreasing need to intervene at the retail level. ${ }^{86}$ It considers regulation at wholesale level less intrusive than that at retail level.

83 For an assessment of the concept's operation in recent times see Martin Cave, 'The Ladder of Investment in Europe, in Retrospect and Prospect' (2014) Telecommunications Policy 674-83.

84 See Maya Bacache-Beauvallet, Marc Bourreau and Germain Gaudin, 'Dynamic Entry and Investment in New Infrastructures: Empirical Evidence from the Fixed Broadband Industry' (2014) 44 Review of Industrial Organization 179-209.

85 Another factor to take into consideration is the role of OTT players, which have contributed to increased competition on the retail side but also to falling revenues.

86 See EECC Proposal, Recitals 159-61. 


\subsection{REGULATORY CHALLENGES}

The European Community is currently engaged in a thorough reform of its telecommunications sector. The reform is prompted by the economy's increasing reliance on telecommunications infrastructure and is happening at a time when Europe is lagging behind the United States and East Asian countries in the deployment and usage of both fixed and wireless high-capacity broadband. Telecommunications are no longer just a part of general infrastructure but a key for future growth. Poorly developed telecoms have adverse effects on the economy and have a negative impact on the society at large. While the EU made significant steps in improving wired and wireless broadband penetration and takeup, remarkable challenges remain in NGN deployment. ${ }^{87}$

The connected world of the future demands ubiquitous high-capacity connectivity, faces the convergence of technologies and services and will witness an unprecedented penetration of over-the-top content (OTT) services - obstacles which 20-year-old principles may not be able to overcome. Today, EU policy documents highlight the fact that the EU remains fragmented both in the carrier and the content layers and that a true Single Market in telecommunications has not yet been achieved. The discussion often revolves around how regulatory intervention can incite investment or, at least, not hinder it. Investing in both wired and wireless network industries is essential for growth but it is also costly, risky and time consuming. The ubiquitous OTT providers are challenging traditional models but are not interested in high-risk investments in infrastructure. While we have witnessed unprecedented levels of innovation at the application layer, the same cannot be said of infrastructure.

Writing good telecommunications laws, at the most basic level, means understanding the nature of the current challenges and building mechanisms for overcoming future ones. The 2002 and 2009 Regulatory Frameworks have partially survived the test of time thanks to their flexibility. Rather than impose rigid solutions, they employed a combination of liberalisation and harmonisation and used a flexible ex ante regulatory technique. This technique is based on competition law principles but provides added flexibility. The 2016 Reform proposes to keep

87 FTTH takeup is above 70 per cent in South Korea and Japan but less than 10 per cent in the EU as of early 2017. While 4G/LTE deployment in the United States stands at more than 65 per cent as of 2016, the same figure for the EU is around 30 per cent. The same can be said of the EU communications capital investment rate. 
all the essential elements of earlier regulatory frameworks, ${ }^{88}$ but that reform faces a number of challenges in the form of the effects of convergence, the extent of statutory obsolescence, the choice of governance models, the extent of regulatory intervention and the investment in NGN.

In the broadest of terms, convergence is the erasure of frontiers between separate information and communications technology (ICT) services, networks and business practices. In the telecommunications world, we talk about the same services being offered through different technologies: telephone calls through fixed, mobile and Internet technologies, terrestrial television through digital aerial broadcasting, cable and Internet streaming, Internet through cable and wireless, messaging through SMS and instant messaging, and so on. The existence of different technologies has made the regulatory environment more challenging. Telecommunications networks based on copper were technologically largely homogenous. This made the regulator's task somewhat simpler. The situation is very different today. Old copper cables still exist to a large extent and are used to provide broadband. ${ }^{89}$ At the same time, broadband is also provided through cable operators' facilities, often packaged together with TV and fixed telephony. Fibre to the home (FTTH) is making progress too. Finally, wireless $3 \mathrm{G}$ and $4 \mathrm{G}$ technologies are slowly but increasingly acting as a replacement for fixed access where demand for speeds and volume is not high. Subjecting these technologies to the same regulatory model may no longer make sense.

The problem here lies in the fact that the Regulatory Framework does not demonstrate the same flexibility that technologies do. There are today three separate regulatory frameworks in the EU: one each for telecommunications, audio-video media services and Internet content. ${ }^{90}$ These frameworks apply to discreet situations within their scope but they also apply to cases which already fall within other frameworks. Thus a telecommunications company under the general telecoms framework but providing a TV package from a partner media company would also be under the audiovisual (AV) and content/IT frameworks. The Convergence Green Paper was an early attempt to understand the nature of the problem and suggest possible ways for dealing with it. ${ }^{91}$ At present, convergence

\footnotetext{
88 For details see Section 2.4.

89 It has been possible to increase speeds through improved technologies.

90 See Section 3.1.

91 Green Paper on the Convergence of the Telecommunications, Media, and Information Technology Sectors and the Implications for Regulation, COM (1997) 623.
} 
remains a problem since three regulatory circles will continue to coexist, causing regulatory overlap.

Another difficulty arises from the fact that large parts of European telecoms laws were created for the legacy technologies and formed around legacy business models. While convergence deals with the existence of multiple legal frameworks covering one technological reality, statutory obsolescence deals with the problem of the timeframe within which a statute can be drafted, voted on, made into law and applied in courts, and within which problems can be identified and changes proposed. In the EU, significant reforms were made in the mid-1990s, 2002, 2009 and 2016, all at intervals of approximately seven years. While this is relatively flexible, it is far beyond the pace of technological change. The standard solution to this problem has been technological neutrality of telecommunications laws - a regulatory principle that means statutes are not bound to specific technologies. While this has been partially successful, it does not resolve the most fundamental clashes which happen at a more fundamental level - between legacy technologies and newer disruptive ones. There the question is not how regulatory framework could be made to apply to new technology but whether it should. The most fundamental conflict of this kind today is the question whether OTT services should be regulated more or traditional services regulated less.

Only some issues lend themselves to simple legal intervention; others require more complicated governance models. Multistakeholder governance models, for example, bring different stakeholders together into dialogue and decision-making processes as well as make them part of the implementation process. Telecommunications networks are not only regulated, that is, subject to national or EU laws; they are also governed. They are subject to industry standards and practices, international formal and informal canons, and similar. This multiplicity of stakeholders provides the required flexibility but makes the task of governing electronic communication more difficult.

One of the most basic questions concerns the scope of regulatory intervention. The choice is usually not between absence of regulation and full regulation, but rather between different degrees of intervention. A general observation is that more stringent regulation has a negative impact on innovation. ${ }^{92}$ On the other hand, a number of fundamental

92 See for example Johannes M. Bauer, 'Regulation and Innovation in Telecommunications', QuelloCenter Working Paper 01-2012, available at https:// pdfs.semanticscholar.org/8d1e/d6d2c8d8a6199e04fadf804db7d7c9803ba8.pdf. 
issues in the telecommunications world are not normally within the power of the executive. A copper switchoff, for example, is a business decision, and any governmental intervention may have unintended consequences and may require protection of various parties involved. Likewise, the deployment of optical fibre to homes and business premises (FTTH) can be part of a government strategy but ultimately remains a commercial enterprise which cannot presently be adequately completed by state alone.

In order to foster investment in NGN, the 2009 Regulatory Framework modified some of the tools already at their disposal. Article 8(5)(d) of the Framework Directive specifically has risk in mind, saying that NRAs need to be

promoting efficient investment and innovation in new and enhanced infrastructures, including by ensuring that any access obligation takes appropriate account of the risk incurred by the investing undertakings and by permitting various cooperative arrangements between investors and parties seeking access to diversify the risk of investment, whilst ensuring that competition in the market and the principle of non discrimination are preserved.

Any reform of EU telecommunications laws should no longer be satisfied with solving problems in individual sectors, but must attempt to address much deeper structural challenges. The Commission made very clear statements in terms of the depth of regulatory intervention and its ultimate aims: ${ }^{93}$

The [EECC] Code will apply market regulation only where end-user interest requires it and where commercial arrangements between operators do not deliver competitive outcomes. The new Code substantially reduces regulation where rival operators co-invest in very high-capacity networks and makes it easier for smaller players to be part of investment projects, thanks to the pooling of costs, the overcoming of scale barriers, etc. New rules make the investment case more predictable for 'first movers' who take the risk to invest in those networks in less profitable areas, such as rural areas.

For a general discussion of how EU lawmaking affects innovation see Jacques Pelkmans and Andrea Renda, Does EU Regulation Hinder or Stimulate Innovation? (19 November 2014) CEPS Special Report No. 96. Available at SSRN: https://ssrn.com/abstract=2528409.

93 European Commission, Press Release, State of the Union 2016: Commission Paves the Way for More and Better Internet Connectivity for All Citizens and Businesses, 14 September 2016. 
The development of next-generation access (NGA) depends, among other things, on the right regulatory model. NGA has been identified as a key factor in the development of future telecommunications but the path for achieving this has not always been clear. The main challenge has been to incentivise investment in NGA while maintaining infrastructure competition. In the United States, the FCC decided not to subject fibre networks to access obligations, ${ }^{94}$ believing that this would disincentivise investment in new networks. At the same time, some East Asian countries have provided state support to further push fibre deployment. The EU did not initially follow this approach, instead initiating proceedings against Germany in 2007 when the former announced that it would temporarily suspend regulation of fibre-based investment. ${ }^{95}$ More recently, however, measures initiated in 2010, 2014 and 2016 have demonstrated that the EU is rethinking its strategy for investment in NGA networks, ${ }^{96}$ taking symmetric regulation seriously for the first time. ${ }^{97}$

94 Section 251 Network Unbundling, 3.12.2014, available at https://www.fcc. gov/general/section-251-network-unbundling.

95 See Shortall and Cave (2015).

96 See Chapter 10.3.

97 BEREC, Report on the Implementation of Symmetric Regulation: Description of Existing Practices and Consideration of Future Challenges, BoR (17) 39, 23.02.2017. 